\title{
Perinatale risikofaktorer for prostatakreft: En prospektiv populasjonsbasert studie
}

\author{
Tom I.L. Nilsen ${ }^{1}$, Pål R. Romundstad ${ }^{1}$, Rebecca Troisi ${ }^{2}$ og Lars J. Vatten ${ }^{1, *}$ \\ (1) Institutt for samfunnsmedisin, Norges teknisk-naturvitenskapelige universitet, Trondheim \\ (2) Division of Epidemiology and Genetics, National Cancer Institute, Bethesda, MD, USA \\ *Korrespondanse: Professor Lars J. Vatten, Institutt for samfunnsmedisin, Norges teknisk-naturvitenskapelige universitet, 7489 Trondheim \\ e-post: lars.vatten@medisin.ntnu telefax: 73597577
}

\begin{abstract}
SAMMENDRAG
Til nå har få studier undersøkt sammenhengen mellom størrelse ved fødsel og risiko for prostatakreft i voksen alder, og resultatene har ikke vært entydige. Vi har undersøkt denne sammenhengen prospektivt, og spesielt fokusert på prostatakreft med metastaser for særlig å studere aggressiv prostatakreft. Studien inkluderer til sammen 19681 menn som ble født ved EC Dahls Stiftelse i Trondheim mellom 1920 og 1958. Ved kobling til Kreftregisteret har vi fått informasjon om hvem som har fått diagnostisert prostatakreft til og med 2001. Informasjon om karakteristika fra fødselen er hentet fra fødejournaler oppbevart ved St. Olavs Hospital i Trondheim. Totalt ble det diagnostisert 159 tilfeller av prostatakreft i oppfølgingsperioden, og av disse hadde 33 metastaser ved diagnosetidspunktet. I analyser av alle tilfeller av prostatakreft, fant vi ingen klar sammenheng mellom størrelse ved fødsel og risiko for sykdommen. Derimot fant vi en positiv sammenheng med fødselsstørrelse for metastatisk sykdom. Menn i den høyeste kvartil av fødselslengde ( $\geq 53 \mathrm{~cm}$ ) hadde en relativ risiko på $2,5(95 \%$ KI 1,0-6,3) for metastatisk prostatakreft sammenliknet med menn i den laveste kvartilen $(<51 \mathrm{~cm})$. Videre fant vi at menn som tilhørte den høyeste kvartilen av både vekt og lengde ved fødsel hadde en relativ risiko på 3,8 (95\% KI $1,2-12,0)$ for metastatisk sykdom sammenliknet med menn i den laveste kvartilen av begge variablene. Disse resultatene gir støtte til hypotesen om at faktorer som er bestemmende for intrauterin vekst kan være av betydning for aggressive former for prostatakreft $i$ voksen alder.
\end{abstract}

Finansiert av Kreftforeningen og Norges forskningsråd

Nøkkelord: prostatakreft $\bullet$ metastaser $\bullet$ fødselsvekt $\bullet$ fødselslengde $\bullet$ hodeomkrets

Oversatt og lettere omarbeidet fra: International Journal of Cancer 2005; 113: 1002-4.

Prostatakreft er den hyppigst forekommende kreftsykdom blant menn i den vestlige verden. Hormonelle faktorer er sannsynligvis av etiologisk betydning, men generelt er det få kjente risikofaktorer for sykdommen. I senere år har det vært økende interesse for å studere om faktorer som virker tidlig i livet er av betydning for å utvikle kroniske sykdommer i voksen alder. Flere studier har rapportert en positiv sammenheng mellom størrelse ved fødsel (fødselsvekt og lengde) og framtidig risiko for brystkreft, som er en annen hormonavhengig kreftsykdom (1-5), men prostatakreft er foreløpig studert i bare noen få undersøkelser (6-10). I en liten svensk studie fant man en sterk positiv sammenheng mellom fødselsvekt og risiko for prostatakreft (6), men påfølgende studier har ikke vist noen klar positiv sammenheng (7-10). I en av disse fant man en svak positiv sammenheng mellom fødselsvekt og risiko for aggressiv prostatakreft, karakterisert av avansert sykdom ved diagnosetidspunktet (8); mens en annen studie viste positiv sammenheng mellom fødselsvekt og mortalitet av prostatakreft (7).

Vi har undersøkt sammenhengen mellom risiko for prostatakreft og fødselsvekt, fødselslengde og hode- omkrets i en prospektiv studie av nesten 20,000 norske menn født mellom 1920 og 1958. Siden prostatakreft er en meget heterogen sykdom, hvor noen svulster vil spre seg raskt, mens andre aldri vil invadere vev ut over prostatakjertelen, kan det hende at sammenhengen med mulige risikofaktorer også viser et differensiert mønster. I denne undersøkelsen har vi særlig studert risiko for avansert sykdom, hvor påviste metastaser ved diagnosetidspunktet er brukt som kriterium på aggressiv, alvorlig sykdom.

\section{MAteriale OG METODE}

\section{Materiale}

Vi har registrert opplysninger fra fødejournaler for perioden 1920-1958 som er oppbevart ved St. Olavs Hospital i Trondheim. Journalførte opplysninger fra alle fødsler som fant sted ved daværende EC Dahls stiftelse for totalt 22270 nyfødte gutter, er registrert. Vi ekskluderte 567 tvillinger, slik at populasjonen i utgangspunktet bestod 21703 nyfødte. Regional komite for medisinsk forskningsetikk har vurdert og anbefalt studien gjennomført. 
Det sentrale personregister ved Statistisk Sentralbyrå fører oppdatert informasjon om hvert enkelt individs vital status, fødested, bosted, og foreldres navn i Norge. I EC Dahls stiftelse var de nyfødte registrert på mors navn, og ved hjelp av barnets fornavn og fødselsdato kombinert med mors navn forsøkte vi å identifisere menn som var født ved EC Dahls stiftelse i perioden 1920 til 1958 og som var i live i 1960. Noen av mennene kunne ikke identifiseres med fødselsnummer, enten fordi de selv var døde før 1960, eller fordi det ikke var informasjon om mors navn i personregisteret. Av i alt 21703 registrerte nyfødte gutter var vi sikre på identiteten til 19681 (91\%), og vi har fulgt disse mennene gjennom kobling til Kreftregisteret til og med 2001.

For menn som var 20 år eller eldre i 1960 (dvs. født før 1941), beregnet vi oppfølgingstid fra 1. januar 1961, og for dem som var født i 1941 eller senere, begynte oppfølgingen ved fylte 20 år. Oppfølgingstiden tok slutt dersom en av følgende begivenheter inntraff: hvis mannen fikk diagnostisert prostatakreft eller annen kreft, dersom han emigrerte ut av landet, eller hvis han døde av annen årsak enn kreftsykdom. For de fleste inntraff ikke noen av disse begivenhetene, og for dem endte oppfølgingen den 31. desember 2001. Prostatakreft ble registrert i Kreftregisteret i henhold til den internasjonale klassifisering av sykdom (ICD, sjuende revisjon, kode 177). Informasjon om kreftsykdommer, inkludert stadium, metastaser og histologi, er basert på rapportering til Kreftregisteret fra patologiske og kliniske avdelinger. Kvaliteten og validiteten til informasjonen om prostatakreft i Kreftregisteret er blitt vurdert til å være meget tilfredsstillende (11).

Fra fødejournalene registrerte vi følgende opplysninger: fødselsvekt (gram), fødselslengde $(\mathrm{cm})$, hodeomkrets (cm), placentas vekt (gram) og svangerskapets varighet (angitt i uker eller måneder). Vi registrerte også tilgjengelig informasjon om maternelle faktorer, slik som mors alder og parietet, hennes høyde, samt hennes sivile og sosiale status. For mødre som var gift da sønnen ble født, brukte vi mannens yrke som indikator på sosioøkonomisk status; dersom moren var ugift, brukte vi hennes eget yrke.

\section{Statistiske metoder}

De kontinuerlige variablene (fødselsvekt, lengde, hodeomkrets og placentas vekt) ble kategorisert $\mathrm{i}$ kvartiler. Ved hjelp av Cox regresjon beregnet vi effekten av hver enkelt variabel i forhold til risiko for prostatakreft, uttrykt som insidens rate ratio (RR) og 95\% konfidensintervall (KI). Vi testet også lineære effekter ved å inkludere kvartiler av de ulike målene på fødselsstørrelse som ordinale variabler i analysen. Vi justerte for alders- og kohorteffekter ved å inkludere fødselsår i 5-års intervaller (1920-24, 1925-29, ..., 1955-58). I multivariable analyser vurderte vi potensielt konfunderende effekter av andre variabler som vi hadde informasjon om, som gestasjonsalder, mors alder, parietet og høyde, samt hennes sivile og sosioøkonomiske status. Dessuten undersøkte vi sammenhengen mellom fødselsstørrelse og alle tilfeller av prostatakreft og i en separat analyse bare tilfeller hvor det var registrert metastaser på diagnosetidspunktet.

\section{RESULTATER}

I løpet av 41 års oppfølgingstid (median $=31,4$ år), ble det diagnostisert 159 nye tilfeller av prostatakreft i kohorten, og av disse var 33 registrert med metastaser på diagnosetidspunktet. Median alder ved diagnose var 65 år (range $=41-81$ år), noe som gjenspeiler den relativt unge aldersfordelingen i kohorten. I løpet av oppfølgingstiden ble 1110 menn sensurert når de fikk en annen kreftform, 1621 ble sensurert da de døde av andre årsaker enn kreft, mens 451 menn ble sensurert da de emigrerte ut av landet og ikke lenger kunne følges opp via Kreftregisteret.

Totalt fant vi en svak positiv sammenheng mellom fødselsvekt og risiko for prostatakreft (Tabell 1). Menn i den høyeste kvartilen av fødselsvekt ( $\geq 3925$ g) hadde en RR på 1,3 (KI 0,8-2,0) sammenliknet med menn i den laveste kvartilen $(<3260 \mathrm{~g})$, men den lineære økningen i risiko over kategoriene av fødselsvekt var ikke statistisk signifikant $(p=0,29)$. Vi fant en tilsvarende positiv sammenheng mellom fødselslengde og prostatakreft, hvor menn i den høyeste kategorien $(\geq 53$ $\mathrm{cm}$ ) hadde en RR på 1,2 (KI 0,7-2,0) sammenlignet med menn i den laveste $(<51 \mathrm{~cm})$. I forhold til hodeomkrets fant vi ingen tydelig sammenheng. Vi justerte for de potensielt konfunderende variablene gestasjonsalder, maternell alder og parietet, samt maternell høyde og sosioøkonomisk status, men dette forandret ikke estimatene. For prostatakreft med metastaser (33 tilfeller) fant vi sterkere sammenheng med fødselsstørrelse, spesielt for fødselslengde (Tabell 2). For menn i den lengste kategorien $(\geq 53 \mathrm{~cm})$ var RR for metastatisk prostatakreft 2,5 (KI 1,0-6,3) sammenliknet med menn i den laveste kategorien $(<51 \mathrm{~cm})$. Ved å sammenlikne menn i den høyeste $(\geq 3925 \mathrm{~g})$ og laveste $(<3260 \mathrm{~g})$ kvartilen av fødselsvekt, fant vi at de som veide mest ved fødselen hadde en RR på 1,5 (KI 0,6-3,7). I tillegg sammenliknet vi menn som var i den høyeste kategorien både for vekt og lengde med menn som var i den laveste kategorien av begge variablene. Resultatet viste at risikoen for metastatisk prostatakreft var nesten fire ganger høyere $(\mathrm{RR}=3,8,95 \% \mathrm{KI}, 1,2-12,0)$ blant dem som var i den største gruppen (data ikke vist). Justering for gestasjonsalder, maternell alder og parieet, samt maternell høyde og sosioøkonomisk status påvirket ikke disse resultatene.

\section{DISKUSJON}

I denne prospektive studien av norske menn, fant vi en klar positiv sammenheng mellom størrelse (lengde og vekt) ved fødsel og risiko for metastatisk prostatakreft. I analyser som inkluderte alle tilfeller av prostatakreft 
Tabell 1. Relativ risiko for prostatakreft relatert til størrelse ved fødsel.

\begin{tabular}{lcccc}
\hline & Antall tilfeller $^{\mathrm{a}}$ & Antall menn $^{\mathrm{a}}$ & ${\text { Relativ risiko }(95 \% \mathrm{KI})^{\mathrm{b}}}$ & p-trend $^{\mathrm{c}}$ \\
\hline $\begin{array}{l}\text { Fødselsvekt (g) } \\
\quad 3265\end{array}$ & 38 & 4969 & & \\
$3265-3590$ & 39 & 4829 & 1,0 & \\
$3595-3920$ & 39 & 5017 & $1,2(0,8-1,9)$ & \\
$\quad 33925$ & 43 & 4861 & $1,3(0,7-1,8)$ & \\
& & & & 0,29 \\
Fødselslengde (cm) & & & & \\
$\quad<51$ & 79 & 6724 & 1,0 & \\
51 & 27 & 3715 & $0,9(0,6-1,4)$ & \\
52 & 35 & 4028 & $1,6(1,1-2,4)$ & \\
$\geq 53$ & 18 & 5205 & $1,2(0,7-2,0)$ & 0,16 \\
& & & & \\
Hodeomkrets (cm) & & & & \\
$<35$ & 42 & 4782 & $0,8(0,5-1,3)$ & \\
35 & 36 & 5092 & $0,9(0,6-1,3)$ & \\
36 & 39 & 5124 & $1,1(0,7-1,8)$ & 0,54 \\
$\geq 37$ & 42 & 4612 & & \\
\hline
\end{tabular}

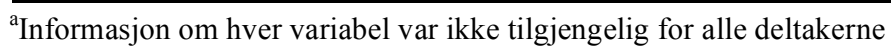

bustert for fødselsår (1920-1924, 1925-1929, ..., 1955-1958)

${ }^{\mathrm{c}}$ Tosidig $p$-verdi for trend i Cox regresjon

Tabell 2. Relativ risiko for metastatisk prostatakreft assosiert med fødselsvekt og fødselslengde.

\begin{tabular}{lcccc}
\hline & Antall tilfeller $^{\mathrm{a}}$ & Antall menn $^{\mathrm{a}}$ & ${\text { Relativ risiko }(95 \% \mathrm{KI})^{\mathrm{b}}}$ & $p$-trend $^{\mathrm{c}}$ \\
\hline Fødselsvekt (g) & & & & \\
$\quad<3260$ & 8 & 4969 & 1,0 & \\
$3265-3590$ & 7 & 4829 & $1,0(0,4-2,8)$ & \\
$3595-3920$ & 8 & 5017 & $1,1(0,4-3,0)$ & \\
$\geq 3925$ & 10 & 4861 & $1,5(0,6-3,7)$ & 0,41 \\
& & & & \\
Fødselslengde (cm) & 18 & 6724 & 1,0 & \\
$\quad<51$ & 6 & 3715 & $0,9(0,4-2,3)$ & \\
51 & 2 & 4028 & $0,5(0,1-2,1)$ & \\
52 & 7 & 5205 & $2,5(1,0-6,3)$ & 0,30 \\
\hline 53 & 2 & & & \\
\hline
\end{tabular}

${ }^{\mathrm{a}}$ Informasjon om hver variabel var ikke tilgjengelig for alle deltakerne

bustert for fødselsår (1920-1924, 1925-1929, .., 1955-1958)

${ }^{\mathrm{c}}$ Tosidig $p$-verdi for trend i Cox regresjon

fant vi imidlertid bare svake sammenhenger med fødselsvekt og fødselslengde. Tidligere har en svensk kohortstudie vist en positiv sammenheng mellom fødselsvekt og samlet risiko for prostatakreft (6), men påfølgende studier har ikke bekreftet en slik sammenheng $(7,9)$. En studie viste imidlertid en positiv sammenheng mellom fødselsvekt og mortalitet av prostatakreft (7). To andre studier fra USA fant heller ingen samlet sammenheng mellom fødselsvekt og risiko for prostatakreft $(8,10)$; men i én av disse fant forskerne en svak positiv sammenheng mellom fødselsvekt og avansert prostatakreft (8).

Tre tidligere studier har hatt informasjon om fødselslengde. To svenske studier fant ingen sammenheng mellom fødselslengde og samlet risiko for prostatakreft $(7,9)$, men en kasus-kontroll studie rapporterte en positiv men svak sammenheng med fødselslengde (10).

I vår undersøkelse var den positive sammenhengen med fødselslengde begrenset til aggressive tilfeller av prostatakreft, det vil si sykdom hvor man hadde registrert metastaser på diagnosetidspunktet. Kombinert med funnene fra tidligere studier tyder våre resultater på at det er en positiv sammenheng mellom størrelse ved fødsel og risiko for prostatakreft. Mye tyder likevel på at sammenhengen er begrenset til avansert sykdom, og kanskje ikke gjelder for lite aggressiv prostatakreft. 
Det prospektive designet er en styrke ved denne undersøkelsen. Det er også en styrke at vi hadde tilgang til informasjon fra journaler med målte, i motsetning til selvrapporterte opplysninger om lengde og vekt ved fødsel. Den komplette oppfølgingen i forhold til insidens av prostatakreft $i$ en stor og uselektert befolkning bidrar også til å styrke validiteten av våre funn. En mulig svakhet ved studien kan være mangelen på informasjon om faktorer i voksen alder som kan ha en potensielt konfunderende effekt, men for prostatkreft er det få, om noen, etablerte risikofaktorer som man kan hevde er klart relatert til størrelse ved fødselen.

Det har tidligere vært påpekt at det intrauterine miljø kan ha betydning for utviklingen av prostatakreft som voksen, og at svangerskapshormoner og vekstfaktorer, som for eksempel østrogen, testosteron og insulin-lik vekstfaktor, kan være involvert (12-14). Resultatene fra denne studien tyder på at intrauterine faktorer kan påvirke risikoen for prostatakreft $\mathrm{i}$ voksen alder, og at effekten særlig kan gjelde for aggressive tilfeller av sykdommen.

\section{REFERANSER}

1. Michels K, Trichopoulos D, Robins JM, Rosner BA, Manson JE, Hunter DJ, Colditz GA, Hankinson SE, Speizer FE, Willett WC. Birthweight as a risk factor for breast cancer. Lancet 1996; 348: 1542-6.

2. De Stavola BL, Hardy R, Kuh D, dos Santos Silva I, Wadsworth M, Swerdlow AJ. Birthweight, childhood growth and risk of breast cancer in a British cohort. Br J Cancer 2000; 83: 964-8.

3. McCormack VA, dos Santos Silva I, De Stavola BL, Mohsen R, Leon DA, Lithell HO. Fetal growth and subsequent risk of breast cancer: results from long term follow up of Swedish cohort. BMJ 2003; 326: 248-53.

4. Ahlgren M, Sørensen T, Wohlfahrt J, Haflidadóttir Á, Holst C, Melbye M. Birth weight and risk of breast cancer in a cohort of 106,504 women. Int J Cancer 2003; 107: 997-1000.

5. Vatten LJ, Maehle BO, Lund Nilsen TI, Tretli S, Hsieh C-C, Trichopoulos D, Stuver SO. Birth weight as predictor of breast cancer: a case-control study in Norway. Br J Cancer 2002; 86: 89-91.

6. Tibblin G, Eriksson M, Cnattingius S, Ekbom A. High birthweight as a predictor of prostate cancer risk. Epidemiology 1995; 6: 423-4.

7. Ekbom A, Hsieh C-C, Lipworth L, Wolk A, Ponten J, Adami HO, Trichopoulos D. Perinatal characteristics in relation to incidence of and mortality from prostate cancer. $B M J$ 1996; 313: 337-41.

8. Platz EA, Giovannucci E, Rimm EB, Curhan GC, Spiegelman D, Colditz GA, Willett WC. Retrospective analysis of birth weight and prostate cancer in the health professionals follow-up study. Am J Epidemiol 1998; 147: 1140-4.

9. Ekbom A, Wuu J, Adami HO, Lu CM, Lagiou P, Trichopoulos D, Hsieh C-C. Duration of gestation and prostate cancer risk in offspring. Cancer Epidemiol Biomarkers Prev 2000; 9: 221-3.

10. Boland LL, Mink PJ, Bushouse SA, Folsom AR. Weight and length at birth and risk of early-onset prostate cancer. Cancer Causes Control 2003; 14: 335-8.

11. Harvei S, Tretli S, Langmark F. Quality of prostate cancer data in the Cancer Registry of Norway. Eur $J$ Cancer 1996; 32A: 104-10.

12. Henderson BE, Bernstein L, Ross RK, Depue RH, Judd HL. The early in utero oestrogen and testosterone environment of blacks and whites: potential effects on male offspring. Br J Cancer 1988; 57: 216-8.

13. Ross RK, Henderson BE. Do diet and androgens alter prostate cancer risk via a common etiologic pathway? $J$ Natl Cancer Inst 1996; 86: 252-4.

14. Trichopoulos D, Lipworth L. Is cancer causation simpler than we thought, but more intractable? Epidemiology 1995; 6: 347-9. 